\title{
Presacral myelolipoma in a geriatric patient
} Alessandro Spizzirri* , Carla Migliaccio, Lorenzo Cattorini, Vincenzo Napolitano, Pamela Del Monaco, Maurizio Bravetti, Marco Coccetta, Roberto Cirocchi, Giammario Giustozzi and Francesco Sciannameo

\author{
Address: Department of General and Emergency Surgery, S. Maria Hospital, Terni - University of Perugia, Italy \\ * Corresponding author
}

from XXI Annual Meeting of The Italian Society of Geriatric Surgery

Terni, Italy. 4-6 December 2008

Published: I April 2009

BMC Geriatrics 2009, 9(Suppl I):A35 doi: 10.1 186/I47I-23I8-9-SI-A35

This abstract is available from: http://www.biomedcentral.com/I47I-23 I8/9/SI/A35

(c) 2009 Spizzirri et al; licensee BioMed Central Ltd.

\section{Background}

Presacral tumors are most frequently benign, occasionally malignant with a slow growth. Their incidence is 1:40000 and they are asymptomatic in the $26-50 \%$ of cases. When visible symptoms occur, these are related to the dimensions of the tumor, to its location and to the presence of infection. We believe all presacral tumors should undergo a surgical resection, even if the patient is asymptomatic and these are more frequently benign tumors.

\section{Materials and methods}

We report the case of a 69-year old woman with a lower abdominal pain associated with paresthesia and hypostenia of the right inferior limb. Digital examination of the rectum let esteem a fixed, mild tender and hard tumor of the posterior external wall of the rectum. The C.T. guided biopsy gave insufficient results for a diagnosis. MRI allowed to appreciate and reveal a solid, dishomogeneous structure, capsulate mass located in the presacral region with diameters of about $9.5 \times 7.5 \times 9 \mathrm{~cm}$, adherent to the body of the sacrum, with connective likely origin, in the absence of lymphoadenopathy of the small basin. Surgical intervention showed a tumor tenaciously adherent to the sacrum.

\section{Results}

Patients with myelipoma are generally old-aged, female and without alterations in the periferic blood slide or hepato-splenomegalia, however these tumors can be asso- ciated with endocrine disfunctions. Usually myelipomas are single and the adrenal gland is the most common location however in a half of the cases reported in literature they are located in the presacral region. They are often asymptomatic and this characteristic could be a good aid for the differential diagnosis with symptomatic tumors or those having a bony envolvement like "cordomi". Usually these neoplasms result capsulate, strictly adherent without infiltrating the neighboring structures, well circumscribed, with variable dimensions up to several $\mathrm{cm}$ in diameters (maximum 12) and weights between 70 and 400 gr.

\section{Conclusion}

In literature the surgical approach to the presacral space is described by anterior or posterior way or a combination of these. The Authors' opinion is that the en-block resection of these tumors with an anterior surgical approach allows a diagnosis of the nature of the disease and it is the best treatment for malignant lesions, which are frequently radio and chemo-resistent. Anyway it is important to consider that these tumors are easily bleeding because of their connections with the presacral venuos plexus. 